\title{
Atorvastatin inhibits homocysteine-induced dysfunction and apoptosis in endothelial progenitor cells
}

\author{
Xiao-mei BAO, Chun-fang WU, Guo-ping LU* \\ Department of Cardiology, Ruijin Hospital, Shanghai Jiao Tong University School of Medicine, Shanghai 200025, China
}

\begin{abstract}
Aim: To investigate the protective effects of atorvastatin on homocysteine (Hcy)-induced dysfunction and apoptosis in endothelial progenitor cells (EPCs) and the possible molecular mechanisms.

Methods: EPCs were divided into six groups: Hcy treatment groups (0, 50, and $500 \mu \mathrm{mol} / \mathrm{L})$ and atorvastatin pretreatment groups $(0.1$, 1 , and $10 \mu \mathrm{mol} / \mathrm{L})$. EPC proliferation, migration, in vitro vasculogenesis activity, and apoptosis rate were assayed by the MTT assay, modified Boyden chamber assay, in vitro vasculogenesis kit, and AnnexinV-FITC apoptosis detection kit, respectively. The level of reactive oxygen species (ROS) in cells was measured using $\mathrm{H}_{2}$ DCF-DA as a fluorescence probe. The activity of NADPH oxidase was evaluated with lucigenin-enhanced chemiluminescence. NO in the supernatant was detected by the nitrate reductase assay. The eNOS mRNA expression and p-eNOS, p-Akt, p-p38MAPK protein expression were measured by RT-PCR and Western blotting analysis, respectively. Caspase-3 activity was determined by colorimetric assay.

Results: Hcy does-dependently impaired the proliferation, migration and in vitro vasculogenesis capacity of EPCs, induced cell apoptosis, increased ROS accumulation and NADPH oxidase activation, and decreased the secretion of NO compared with the control group $(P<0.05$ or $P<0.01)$. The detrimental effects of Hcy were attenuated by atorvastatin pretreatment. Furthermore, Hcy caused a significant downregulation of eNOS mRNA, p-eNOS, and p-Akt protein expression as well as an upregulation of p-p38MAPK protein expression and caspase-3 activity. These effects of Hcy on EPCs were reversed by atorvastatin in a does-dependent manner. Conclusion: Atorvastatin inhibited homocysteine-induced dysfunction and apoptosis in endothelial progenitor cells, which may be related to its effects on suppressing oxidative stress, up-regulating Akt/eNOS and down-regulating the p38MAPK/caspase-3 signaling pathway.
\end{abstract}

Keywords: atorvastatin; homocysteine; endothelial progenitor cells; NADPH oxidase; Akt/eNOS; p38MAPK; caspase-3

Acta Pharmacologica Sinica (2010) 31: 476-484; doi: 10.1038/aps.2010.22; published online 22 Mar 2010

\section{Introduction}

Our previous study has found that Hcy may induce ROS accumulation and endothelial cell apoptosis in human umbilical vein endothelial cells (HUVECs) via activating NADPH oxidase-related oxidative stress and the p38MAPK signaling pathway $^{[1]}$. Recent studies have suggested that endothelial progenitor cells (EPCs) may contribute to neovasculogenesis and reendothelialization of damaged blood vessels to maintain the endothelium ${ }^{[2,3]}$. Some cardiovascular diseases (CVD) and cardiovascular risk factors are associated with lower numbers and dysfunction of circulating EPCs ${ }^{[4-6]}$. Patients or mice with hyperhomocysteinemia (HHcy) have lower numbers of EPCs with impaired activities ${ }^{[6,7]}$. Moreover, an in vitro experi-

\footnotetext{
* To whom correspondence should be addressed.

E-mail gplu52@yahoo.com.cn

Received 2009-09-09 Accepted 2010-01-29
}

ment has shown that Hcy decreased the numbers of EPCs and impaired their proliferation, migration, adhesion and in vitro vasculogenesis capacity ${ }^{[8]}$. However, the underlying mechanisms responsible for the detrimental effects of Hcy on EPCs remain incompletely elucidated.

One explanation accounting for the reduced capacity of EPCs that is induced by Hcy might be the increased apoptosis of $\mathrm{EPCs}^{[9,10]}$. Some reports have suggested the tolerance of EPCs against oxidative stress by demonstrating that one of the characteristics of EPC is a dominant expression of antioxidative molecules, such as superoxide dismutase ${ }^{[11,12]}$. However, other reports ${ }^{[13,14]}$ have shown that apoptotic progenitor cells might be the result of oxidative stress. Hcy seems to promote the formation of ROS primarily by a biochemical mechanism involving endothelial nitric oxide synthase (eNOS) and NADPH oxidase (Nox) activation ${ }^{[15,16]}$. Excessive generation of ROS and reactive nitrogen species may result in cytotoxic 
oxidative stress, which leads to endothelial dysfunction and plays a critical role in the progressive deterioration of vessel structure and function ${ }^{[17]}$. The expression and phosphorylation of the Akt/eNOS signaling pathway are essential for the survival, migration, and angiogenesis of EPCs ${ }^{[18,19]}$. p38 mitogen-activated protein kinase (p38MAPK), a downstream target of proinflammatory cytokines and oxidative stress ${ }^{[20]}$, is also involved in EPC apoptosis ${ }^{[21]}$. Recently, it has been demonstrated that Hcy-mediated EPC apoptosis is associated with caspase- 8 , cytochrome- $c$ release, and caspase- 3 activation ${ }^{[9,10]}$. Increased ROS, acting as an upstream factor for mitochondrial membrane depolarization, induces mitochondria to release cytochrome- $c$ and caspases, resulting in eventual cellular apoptosis and dysfunction.

Synthetic 3-hydroxy-3-methylglutaryl coenzyme A (HMGCoA) reductase inhibitors (statins) have pleiotropic effects, including anticoagulant and anti-inflammatory actions, to reduce the morbidity and mortality of CVD apart from their lipid-lowering effects ${ }^{[22]}$. Statins have been found to reduce oxidative stress-induced apoptosis of endothelial cells ${ }^{[1]}$ and restore the survival and function of EPCs ${ }^{[13,18,23]}$. These effects may contribute to both ischemia-induced neovascularization and endothelial regeneration. Recent studies ${ }^{[18,23]}$ have demonstrated that statins can phosphorylate the serine/threonine kinase Akt in EPCs and induce its downstream substrate eNOS activation. However, different types and concentrations of statins may have different effects on EPCs ${ }^{[24]}$.

Based on these considerations, we tested the hypothesis that Hcy-induced EPC dysfunction is initiated by oxidative stress, which inhibits Akt/eNOS, activates p38MAPK and caspase-3, and causes apoptosis in EPCs. The underlying protective effects of atorvastatin involve reducing oxidative stress from Nox and modulating Akt/eNOS, p38MAPK, and caspase-3 signaling pathways in EPCs.

\section{Materials and methods Materials}

EGM-2 endothelial medium and EGM-2-MV-SingleQuots were obtained from Clonetics (San Diego, CA, USA). Fetalbovine serum (FBS) was obtained from Gibco (Gaithersburg, MD, USA). Cell culture materials were from Costar (Corning, NY, USA). Hcy, NADPH, lucigenin, fibronectin (FN) and anti- $\beta$-actin were obtained from Sigma-Aldrich (St Louis, $\mathrm{MO}, \mathrm{USA}) . \mathrm{H}_{2}$ DCF-DA was purchased from Calbiochem (Darmstadt, Germany). Atorvastatin was purchased from the National Institute for the Control of Pharmaceutical and Biological Products and dissolved in DMSO (1\% v/v) to prepare the solution of $10 \mathrm{mmol} / \mathrm{L}$ atorvastatin, which was diluted to target concentrations before the test. Anti-p-eNOS, anti-pAkt and anti-p-p38MAPK were purchased from Cell Signaling Technology (Danvers, MA, USA). Other reagents were indicated in the article.

\section{Isolation and cultivation of EPCs}

EPCs were isolated and cultured according to previously described techniques ${ }^{[4,8]}$. Briefly, mononuclear cells (MNCs) were isolated from mouse bone marrow by Ficoll density gradient centrifugation and cultured on human FN-coated dishes in EGM-2 endothelial medium supplemented with EGM-2-MV-SingleQuots and 20\% FBS. After $3 \mathrm{~d}$ in culture, non-adherent cells were removed by washing with phosphate buffered saline (PBS), and adherent cells were incubated in fresh medium for another $4 \mathrm{~d}$. The EPCs were made quiescent by incubation in FBS-free medium for $24 \mathrm{~h}$ before stimulation.

\section{Identification of EPCs}

Fluorescent chemical detection of EPCs was performed on attached MNCs after $7 \mathrm{~d}$ in culture. Direct fluorescent staining was used to detect dual binding on FITC-labeled Ulex europaeus agglutinin (UEA-1; Sigma) and 1,1-dioctadecyl-3, 3, 3, 3-tetramethylindocarbocyanine (DiI)-labeled acetylated low-density lipoprotein (acLDL; Molecular Probe). Cells were first incubated with acLDL $(10 \mu \mathrm{g} / \mathrm{mL})$ at $37^{\circ} \mathrm{C}$ for $4 \mathrm{~h}$ and later fixed with $2 \%$ paraformaldehyde for $15 \mathrm{~min}$. After being washed, the cells were reacted with UEA-1 $(10 \mu \mathrm{g} / \mathrm{mL})$ for $1 \mathrm{~h}$. After being stained, samples were viewed with an inverted fluorescent microscope (Olympus). Cells demonstrating double-positive fluorescence were identified as differentiating EPCs ${ }^{[4,8]}$. To examine the expression of surface markers on EPCs, cells were incubated for $30 \mathrm{~min}$ at $4{ }^{\circ} \mathrm{C}$ with phycoerythrin (PE)-conjugated anti-mouse VEGFR-2 (eBioscience) or fluorescein isothiocyanate (FITC)-conjugated anti-mouse CD34 and CD133 antibodies (eBioscience). The cells were then fixed in $2 \%$ paraformaldehyde for $15 \mathrm{~min}$ and quantitatively analyzed with a flow cytometer (Becton Dickinson).

\section{Migration assay}

EPC migration was evaluated using a modified Boyden chamber assay. In brief, isolated EPCs were detached using $0.25 \%$ trypsin, harvested by centrifugation, resuspended in $500 \mu \mathrm{L}$ EGM-2 and counted. Then $2 \times 10^{4}$ EPCs were placed in the upper chamber of a modified Boyden chamber. Vascular endothelial growth factor (VEGF) in EGM-2 medium at 100 $\mathrm{mg} / \mathrm{L}$ was placed in the lower compartment of the chamber. After 24 -h incubation at $37^{\circ} \mathrm{C}$, the lower side of the filter was washed with PBS and fixed with $2 \%$ paraformaldehyde. For quantification, cells were stained with Giemsa solution. Cells migrating into the lower chamber were counted manually in three random microscopic fields.

\section{In vitro vasculogenesis assay}

The in vitro vasculogenesis assay was performed with the In Vitro Angiogenesis Assay Kit (Chemicon). The protocol was according to the manufacturer's instructions. ECMatrix ${ }^{\mathrm{TM}}$ solution was thawed on ice and then mixed with 10× ECMatrix ${ }^{\mathrm{TM}}$ diluent buffer and placed in a 96-well tissue culture plate at $37^{\circ} \mathrm{C}$ for $1 \mathrm{~h}$ to allow the matrix solution to solidify. EPCs were harvested and replanted (10 000 cells/well) on top of the solidified ECM matrix in the EBM-2 medium supplemented with $0.5 \%$ BSA and VEGF $(100 \mathrm{mg} / \mathrm{L})$. Cells were incubated at $37^{\circ} \mathrm{C}$ for $24 \mathrm{~h}$. Tubule formation was inspected under an inverted light microscope at $200 \times$ magnification. 
Tubule formation was defined as a structure exhibiting a length four times its width. Three independent fields were assessed for each well. The average number of tubules/200x field was determined.

\section{Cellular apoptosis detected by flow cytometry}

EPCs were seeded in 12-well plates and pre-cultured at $37^{\circ} \mathrm{C}$ for $24 \mathrm{~h}$. After different treatment for $24 \mathrm{~h}$, the cells were collected and treated as per the protocol in the Annexin V-FITC Apoptosis Detection Kit (Becton Dickinson), and the percentages of apoptotic cells were determined by flow cytometer (BD, USA). Cells were measured with a FACSCalibur (Becton Dickinson, USA). Results were analyzed by Cell Quest Pro software (Becton Dickinson).

\section{Measurement of ROS production}

To evaluate ROS production by EPCs, the membrane permeable indicator $\mathrm{H}_{2}$ DCF-DA was employed. The cells were loaded with $10 \mu \mathrm{mol} / \mathrm{L} \mathrm{H}_{2}$ DCF-DA in serum-free medium at $37^{\circ} \mathrm{C}$ for $30 \mathrm{~min}$ and then washed twice with PBS. After different treatments, the cells were monitored with a flow cytometer (BD, USA) at an excitation wavelength of $488 \mathrm{~nm}$ and an emission wavelength of $525 \mathrm{~nm}$. ROS were determined by comparing the changes in fluorescence intensity with those of the control.

\section{Determination of NADPH oxidase activity}

The lucigenin-derived enhanced chemiluminescence assay was used to determine NADPH oxidase activity in EPCs. Quiescent cells were starved by serum deprivation for $24 \mathrm{~h}$ and treated as indicated, washed twice with ice-cold PBS (pH 7.4) and centrifuged at $2000 \times g$ for $5 \mathrm{~min}$. The pellet was resuspended in ice-cold buffer ( $\mathrm{pH}$ 7.0) containing $1 \mathrm{mmol} / \mathrm{L}$ ethylene glycol tetraacetic acid (EGTA), protease inhibitors, and 150 $\mathrm{mmol} / \mathrm{L}$ sucrose. Then, the cells were lysed. The total protein concentration was determined using a Bradford assay and adjusted to $1 \mathrm{mg} / \mathrm{mL}$. Two hundred microliters of protein sample, including $5 \mu \mathrm{mol} / \mathrm{L}$ lucigenin, were measured over 6 min in quadruplicate using NADPH $(100 \mu \mathrm{mol} / \mathrm{L})$ as a substrate in a luminometer counter (Berthold luminometer centro LB 960, Germany). Data were collected at 2-min intervals in order to measure relative changes in NADPH oxidase activity.

\section{Measurement of NO production}

Quiescent cells were starved by serum deprivation for $24 \mathrm{~h}$ and treated as indicated. The production of $\mathrm{NO}$ was determined by assaying the concentration of NO in the culture supernatant. The protocol was according to the manufacturer's instructions (Jiancheng Technology).

\section{RNA extraction and RT-PCR analysis}

RNA was extracted with Trizol isolation reagent (Invitrogen, USA). Sample RNA content was quantified by measuring absorbance at $260 \mathrm{~nm}$. Reverse-transcription (RT) was performed with the One Step RT-PCR Kit (Promega, USA) according to the manufacturer's instructions. Primers were synthe- sized according to motif: 5'-TCAGGCAGCCTAACTCCTGT-3' (e-NOS, sense), 5'-GAAGATATCTCGGGCAGCAG-3' (e-NOS, anti-sense); 5' -AGATGTGGATCACAAGCAGGAGT-3' $(\beta$-actin, sense) and 5'-GCAATCAAAGTCCTCGGCCACATT-3' ( $\beta$-actin, anti-sense). A total of $50 \mu \mathrm{L}$ of reaction mixture contained $4 \mu \mathrm{L}$ RT product, $1.25 \mathrm{U}$ Taq DNA polymerase, $1 \mu \mathrm{L}$ PCR Nucleotide Mix, $0.1 \mu \mathrm{mol} / \mathrm{L}$ primer, and $5 \mu \mathrm{L}$ 10× Taq DNA polymerase buffer (Promega, USA). The reaction mixture was incubated in a thermocycler (Gene AMP PCR System 9700, USA) programmed to pre-denature at $95^{\circ} \mathrm{C}$ for $5 \mathrm{~min}$. Thirty-five cycles were denatured at $95^{\circ} \mathrm{C}$ for $45 \mathrm{~s}$, annealed at $60^{\circ} \mathrm{C}$ for $1 \mathrm{~min}$, and extended at $72{ }^{\circ} \mathrm{C}$ for $1 \mathrm{~min}$. The last cycle was followed by incubation at $72{ }^{\circ} \mathrm{C}$ for $10 \mathrm{~min}$ and cooling to $4{ }^{\circ} \mathrm{C}$. The PCR products were analyzed in $1.5 \%$ $(v / v)$ agarose gels. Densitometry was performed using Quantity One software. Each mRNA band was normalized with internal standard $\beta$-actin mRNA.

\section{Western blot analysis}

Following treatment, cells were washed with ice-cold PBS and lysed as described previously ${ }^{[25]}$. The protein concentration was determined by the Bradford method. Ten $\mu \mathrm{L}$ of protein was loaded in each lane and subjected to $9 \%$ sodium dodecyl sulfate-polyacrylamide gel electrophoresis (SDS-PAGE) and then transferred to a polyvinylidene difluoride (PVDF) membrane. The blots were probed with antibodies against p-eNOS, p-Akt or p-p38MAPK. Horseradish peroxidase-conjugated secondary antibodies were used in conjunction with an ECL chemiluminescence detection system (Amersham, UK). Staining was quantified by scanning densitometry.

\section{Measurement of caspase- 3 activity}

The activity of caspase- 3 was evaluated using a colorimetric activity assay kit (Chemicon International Molecular, Temecula, CA) according to the manufacturer's instructions. The cells were briefly lysed in a lysis buffer for $30 \mathrm{~min}$ on an ice bath. The lysed cells were centrifuged at $12000 \times g$ for $10 \mathrm{~min}$. After the protein concentration was determined, $100 \mu \mathrm{g}$ of the protein was incubated with $50 \mu \mathrm{L}$ of a reaction buffer and $5 \mu \mathrm{L}$ of the caspase-3 substrate (Ac-DEVD-pNA) on a 96-well plate. The activity of caspase- 3 was determined using a spectrophotometer at $405 \mathrm{~nm}$, and the results were expressed as the fold increase over the mean value of the control.

\section{Statistical analysis}

The obtained data were presented as a mean \pm standard deviation (SD) for a replicate experiment. One-way ANOVA and Dunnett's test in SPSS13.0 software were used for statistical analysis and $P<0.05$ was considered statistically significant.

\section{Results}

\section{Characterization of EPCs}

Total MNCs isolated from bone marrow of C57BL/6J mice and cultured for $7 \mathrm{~d}$ exhibited spindle-shaped, endothelium cell-like morphology. EPCs were characterized as adherent cells that were double positive for Dil-ac-LDL uptake and 

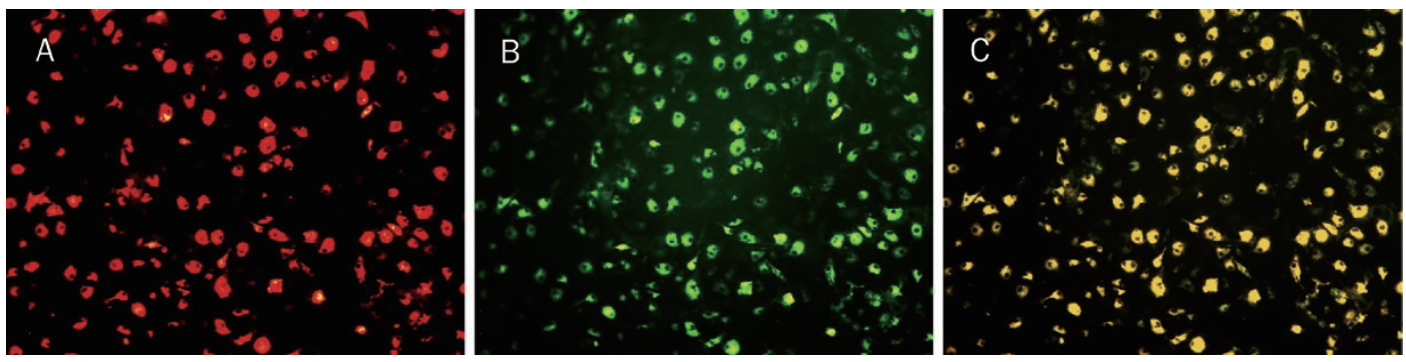

Figure 1. Identification of endothelial progenitor cells $(\times 200)$. After $7 \mathrm{~d}$ of culture, the attached cells were spindle shaped. (A) Red fluorescence represented positive cells with Dil-ac-LDL. (B) Green fluorescence represented positive cells with FITC-UEA-I. (C) Yellow fluorescence represented differentiated endothelial progenitor cell-like adherent cells were double-positive stained with uptake of Dil-ac-LDL and binding on FITC-UEA-I.

UEA-1 binding by fluorescent microscopy (Figure 1). Most adherent cells $(95 \% \pm 5.6 \%)$ took up Dil-ac-LDL and bound with UEA-1 after 7-d culture. This was confirmed by demonstrating the expression of well-established cell surface markers like VEGFR-2 (69.46\% $\pm 3.8 \%)$, CD34 $(22.05 \% \pm 2.3 \%)$ and CD133 $(13.1 \% \pm 4.2 \%)$.

\section{Atorvastatin improved EPC function}

Incubation of EPCs with different concentrations of Hcy (50 and $500 \mu \mathrm{mol} / \mathrm{L}$ ) for $24 \mathrm{~h}$ significantly impaired cellular proliferation, migration, and in vitro vasculogenesis function compared with the control group $(P<0.05$ or $P<0.01$, Table 1$)$. The detrimental effects of $500 \mu \mathrm{mol} / \mathrm{L}$ Hcy on EPC function were attenuated significantly by pretreatment of EPCs with atorvastatin ( 1 and $10 \mu \mathrm{mol} / \mathrm{L})$ for $30 \mathrm{~min}$ compared with the $500 \mu \mathrm{mol} / \mathrm{L}$ Hcy group ( $P<0.05$ or $P<0.01$, Table 1$)$. Representative pictures of the tube formation of EPCs with different treatments are shown (Figure 2). EPCs incubated on ECMatrix for $24 \mathrm{~h}$ formed an extensive and enclosed tube network. Hcy impaired the ability of EPCs to form this tube network. The total length of the tube network was decreased and the tube network was severely disrupted, resulting in an incomplete and sparse tube network. Atorvastatin restored the ability of EPCs to form a tube network.

\section{Atorvastatin inhibited EPCs apoptosis}

The EPC apoptosis induced by Hcy was examined at different concentrations of Hcy $(0,50$, and $500 \mu \mathrm{mol} / \mathrm{L})$ for $24 \mathrm{~h}$. The apoptosis rate of EPCs increased apparently at $500 \mu \mathrm{mol} / \mathrm{L}$
Hcy (treated for $24 \mathrm{~h}$ ), compared with the control group $(P<0.01$, Table 1$)$. To observe the effects of atorvastatin on Hcy-induced apoptosis of EPCs, different concentrations of atorvastatin $(0.1,1$, and $10 \mu \mathrm{mol} / \mathrm{L})$ were added $30 \mathrm{~min}$ before $500 \mu \mathrm{mol} / \mathrm{L}$ Hcy stimulation. As shown in Table 1, atorvastatin inhibited EPC apoptosis induced by $500 \mu \mathrm{mol} / \mathrm{L}$ Hcy in a dose-dependent manner, and the more inhibitory effect was reached at $10 \mu \mathrm{mol} / \mathrm{L}$.

\section{Atorvastatin decreased ROS production and NADPH oxidase activity}

To determine whether oxidative stress was involved in Hcyinduced EPC apoptosis and dysfunction, the changes in ROS production and NADPH oxidase activity among different groups was observed. First, intracellular ROS levels using the ROS-sensitive fluorescent probe, $\mathrm{H}_{2}$ DCF-DA was measured, using a flow cytometer. Hcy at 50 and $500 \mu \mathrm{mol} / \mathrm{L}$ increased DCF fluorescence in a concentration-dependent manner $(222 \% \pm 31 \%, 392 \pm 53 \%$ vs control group: $100 \%, P<0.01$, Figure 3$)$. Atorvastatin (1 and $10 \mu \mathrm{mol} / \mathrm{L})$ markedly blunted the production of ROS induced by $500 \mu \mathrm{mol} / \mathrm{L}$ Hcy for 24 h $(271 \% \pm 26 \%, 201 \% \pm 31 \%$ vs $500 \mu \mathrm{mol} / \mathrm{L} \mathrm{Hcy:} 392 \% \pm 53 \%$, Figure 3A). Further, we measured NADPH oxidase activity with lucigenin-enhanced chemiluminescence. Stimulation with Hcy for $24 \mathrm{~h}$ led to a concentration-dependent increase of NADPH oxidase activity to $131 \% \pm 16 \%$ at $50 \mu \mathrm{mol} / \mathrm{L}$ Hcy and $208 \% \pm 24 \%$ at $500 \mu \mathrm{mol} / \mathrm{L} \mathrm{Hcy}$. Pretreatment of the cells with atorvastatin $(0.1,1$, and $10 \mu \mathrm{mol} / \mathrm{L})$ significantly reduced the Hcy-dependent NADPH oxidase activation by $16.83 \%, 26.92 \%$,

Table 1. Changes of function and apoptosis of endothelial progenitor cells. Mean \pm SD. $n=6 .{ }^{b} P<0.05,{ }^{c} P<0.01$ vs $\mathrm{Hcy} 0 \mu \mathrm{mol} / \mathrm{L}$ group. ${ }^{\mathrm{e}} P<0.05$, ${ }^{\mathrm{f}} \mathrm{P}<0.01$ vs Hcy $500 \mu \mathrm{mol} / \mathrm{L}$ group.

\begin{tabular}{|c|c|c|c|c|}
\hline Group & Proliferation & Migration & Vasculogenesis & Apoptosis rate \\
\hline Hcy $0 \mu \mathrm{mol} / \mathrm{L}$ & $0.693 \pm 0.039$ & $25.67 \pm 6.03$ & $21.33 \pm 5.13$ & $2.28 \pm 0.16$ \\
\hline Hcy $50 \mu \mathrm{mol} / \mathrm{L}$ & $0.516 \pm 0.055^{c}$ & $17.33 \pm 5.13^{b}$ & $12.33 \pm 3.2^{c}$ & $2.83 \pm 0.25$ \\
\hline Hcy $500 \mu \mathrm{mol} / \mathrm{L}$ & $0.334 \pm 0.061^{c}$ & $7.33 \pm 2.52^{c}$ & $6.67 \pm 2.08^{\mathrm{c}}$ & $9.74 \pm 0.44^{c}$ \\
\hline Hcy $500 \mu \mathrm{mol} / \mathrm{L}+$ Ator $0.1 \mu \mathrm{mol} / \mathrm{L}$ & $0.455 \pm 0.094^{\mathrm{e}}$ & $11.67 \pm 3.06$ & $10.67 \pm 2.08$ & $7.67 \pm 0.42^{f}$ \\
\hline Hcy $500 \mu \mathrm{mol} / \mathrm{L}+$ Ator $1 \mu \mathrm{mol} / \mathrm{L}$ & $0.479 \pm 0.069^{e}$ & $15.33 \pm 2.08^{\mathrm{e}}$ & $16.67 \pm 3.51^{f}$ & $6.51 \pm 0.48^{f}$ \\
\hline
\end{tabular}

Ator: atorvastatin 

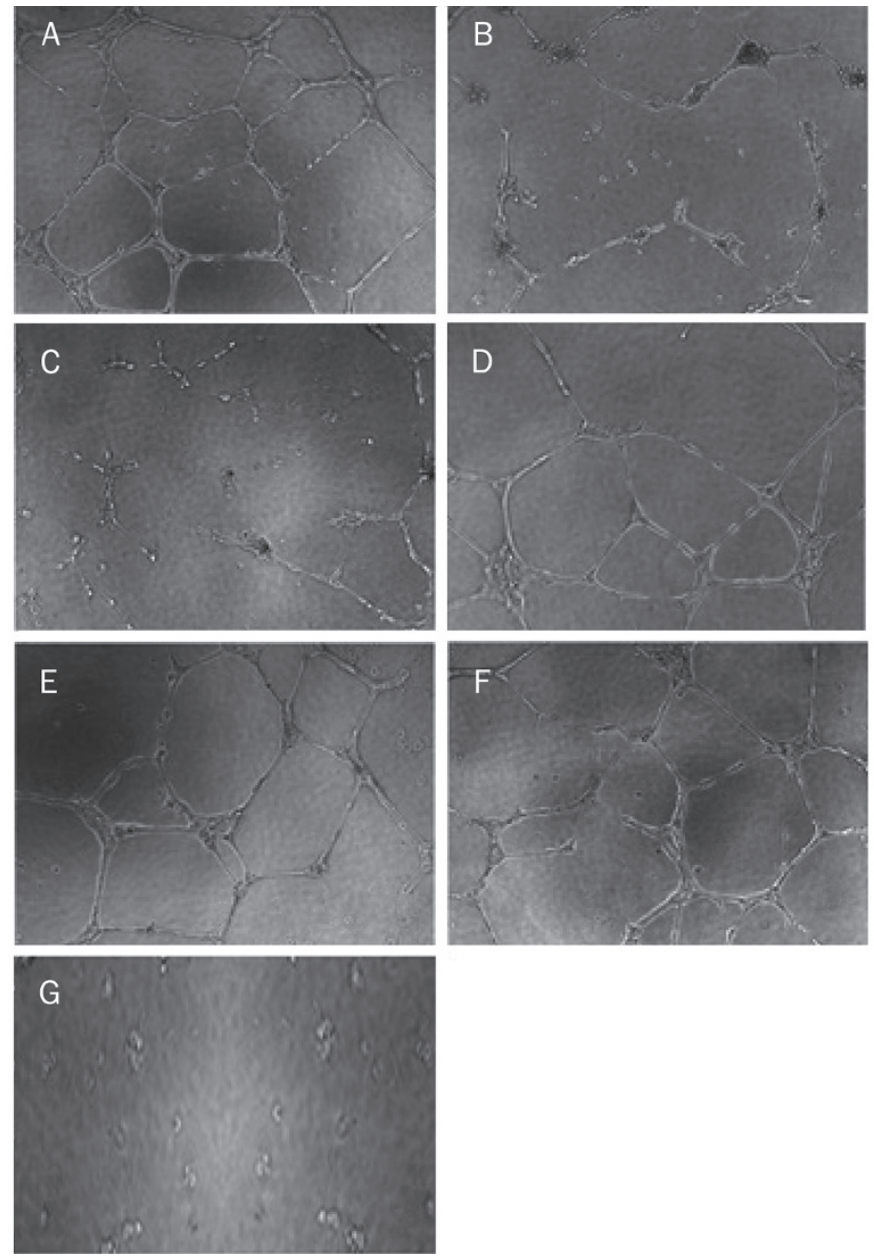

Figure 2. In vitro vasculogenesis activity of endothelial progenitor cells (×200). (A) $0 \mu \mathrm{mol} / \mathrm{L} H c y$ group; (B) $50 \mu \mathrm{mol} / \mathrm{L} \mathrm{Hcy} \mathrm{group;} \mathrm{(C)} 500 \mu \mathrm{mol} / \mathrm{L}$

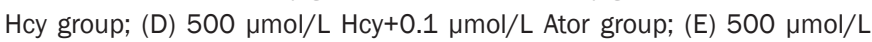

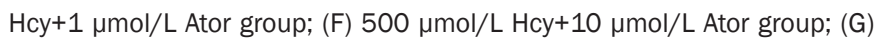
negative control group. Ator: atorvastatin.

and $34.13 \%$, respectively (Figure 3B).

Atorvastatin increased NO production, eNOS mRNA, and p-eNOS expression

The NO concentrations in the culture supernatant of EPCs decreased apparently at $500 \mathrm{\mu mol} / \mathrm{L}$ Hcy treated for $24 \mathrm{~h} \mathrm{com-}$ pared with the control group $(36.24 \pm 5.64 \mu \mathrm{mol} / \mathrm{L}$ vs $61.20 \pm 7.35$ $\mu \mathrm{mol} / \mathrm{L}, P<0.01)$ (Figure $4 \mathrm{~A}$ ). Pretreatment with atorvastatin for 30 min markedly attenuated the decrease in NO induced by Hcy $(47.56 \pm 7.79 \mu \mathrm{mol} / \mathrm{L}, 55.63 \pm 4.43 \mu \mathrm{mol} / \mathrm{L}$ vs $500 \mu \mathrm{mol} / \mathrm{L}$ Hcy: $36.24 \pm 5.64 \mu \mathrm{mol} / \mathrm{L}, P<0.05$ or $P<0.01$ ) (Figure $4 \mathrm{~A}$ ). Further, we set the eNOS mRNA expression of the control group equal to $100 \%$. Figure $4 \mathrm{~B}$ demonstrates the significant downregulation of eNOS mRNA expression when EPCs were incubated with $500 \mu \mathrm{mol} / \mathrm{L}$ Hcy $(43.8 \% \pm 3.8 \%$ vs $100 \% ; P<0.01)$. Atorvastatin up-regulated eNOS mRNA expression $(0.1,1$, and $10 \mu \mathrm{mol} / \mathrm{L}$ atorvastatin groups: $70.5 \% \pm 4.7 \%, 92.8 \% \pm 5.4 \%$, $103.4 \% \pm 4.6 \%$ vs $500 \mu \mathrm{mol} / \mathrm{L}$ Hcy group: $43.8 \% \pm 3.8 \%$; $P<0.05$ ).
A

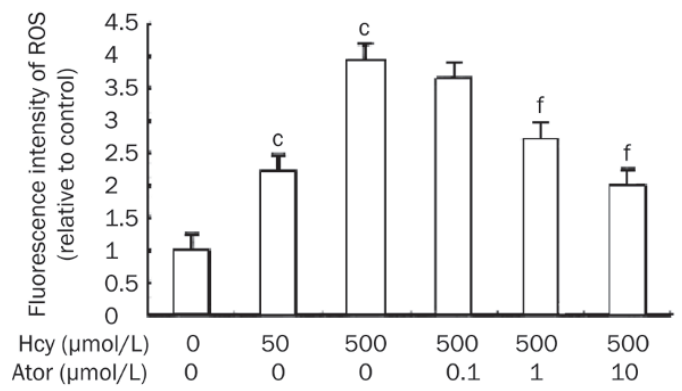

B

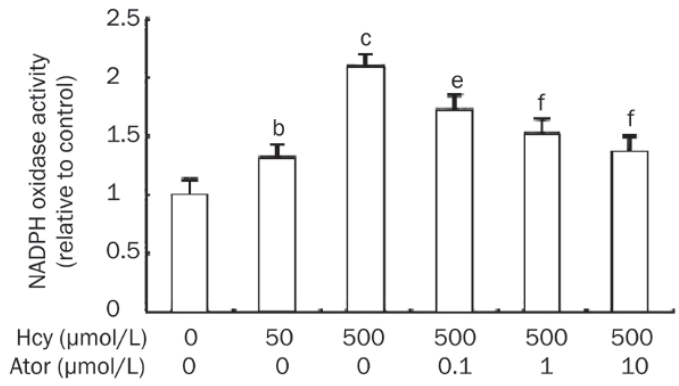

Figure 3. Atorvastatin decreased ROS production and NADPH oxidase activity. (A) Effects of atorvastatin on Hcy-induced ROS within EPCs. Cells were incubated with $10 \mu \mathrm{mol} / \mathrm{L} \mathrm{H}_{2}$ DCF-DA for $30 \mathrm{~min}$ at $37^{\circ} \mathrm{C}$ and pre-incubated with atorvastatin $(0.1-10 \mu \mathrm{mol} / \mathrm{L})$ for $30 \mathrm{~min}$ before the addition of $500 \mu \mathrm{mol} / \mathrm{L} \mathrm{Hcy}$. The relative fluorescence intensity of cells was calculated relative to untreated control cells. (B) Effects of atorvastatin on NADPH oxidase activity. Pretreatment of cells with atorvastatin (0.1-10 $\mathrm{mol} / \mathrm{L}) 30 \mathrm{~min}$ prior to $500 \mu \mathrm{mol} / \mathrm{L} \mathrm{Hcy}$ reduced NADPH oxidase activation. NADPH oxidase activity was assessed as lucigenin-enhanced chemiluminescence using NADPH as a substrate. Results are the mean $\pm S D$ from three independent experiments. ${ }^{b} P<0.05$, ${ }^{\mathrm{c}} P<0.01$ vs $0 \mu \mathrm{mol} / \mathrm{L} \mathrm{Hcy}$ group. ${ }^{\mathrm{e}} P<0.05,{ }^{\mathrm{f}} P<0.01$ vs $500 \mu \mathrm{mol} / \mathrm{L}$ Hcy group. Ator: atorvastatin.

Hcy also reduced eNOS phosphorylation (500 $\mu \mathrm{mol} / \mathrm{L}$ Hcy group: $20.8 \% \pm 5.9 \%$ vs control: $100 \% ; P<0.01)$. Atorvastatin $(0.1,1$, and $10 \mu \mathrm{mol} / \mathrm{L})$ inhibited the downregulation of eNOS phosphorylation $(73.6 \% \pm 6.1 \%, 84.8 \% \pm 7.4 \%, 124.7 \% \pm 7.2 \%$ vs 500 umol/L Hcy group: $20.8 \% \pm 5.9 \%$; $P<0.01$, Figure 4 C).

\section{Atorvastatin increased $\mathrm{p}$-Akt and decreased p-p38MAPK protein expression}

To explore whether $\mathrm{p}$-Akt and p38MAPK signaling were involved in the Hcy-induced EPC apoptosis and dysfunction, immunoblots were performed. Hcy induced a downregulation of Akt phosphorylation $(500 \mu \mathrm{mol} / \mathrm{L}$ Hcy group: $30.3 \% \pm 5.5 \%$ vs control group: $100 \%$; $P<0.01)$. However, atorvastatin restored the phosphorylation of Akt $(0.1,1$, and $10 \mu \mathrm{mol} / \mathrm{L}$ atorvastatin groups: $45.1 \% \pm 1.7 \%, 75.8 \% \pm 1.6 \%$, $79.9 \% \pm 2.1 \%$ vs $500 \mu \mathrm{mol} / \mathrm{L}$ Hcy group: $30.3 \% \pm 5.5 \%$; $P<0.01$ ) (Figure 5A). In contrast, incubation of EPCs with 50 or 500 $\mu \mathrm{mol} / \mathrm{L}$ Hcy for $24 \mathrm{~h}$ increased p-p38MAPK expression by 3.3fold and 7.2-fold, respectively $(P<0.01)$, whereas atorvastatin inhibited the upregulation of $\mathrm{p}$-p38MAPK protein expression in a concentration-dependent manner $(0.1,1$, and $10 \mu \mathrm{mol} / \mathrm{L}$ 
A

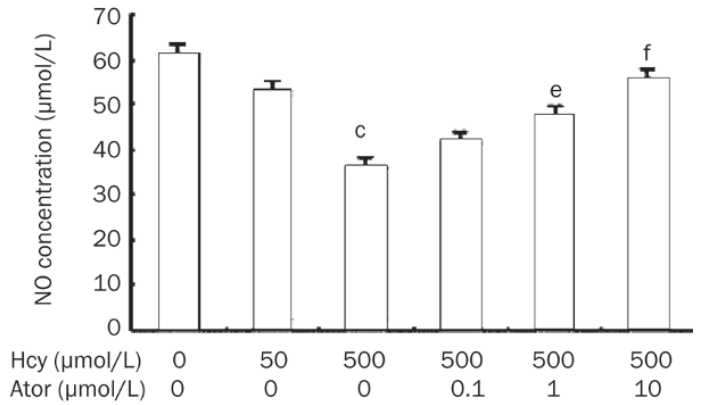

B
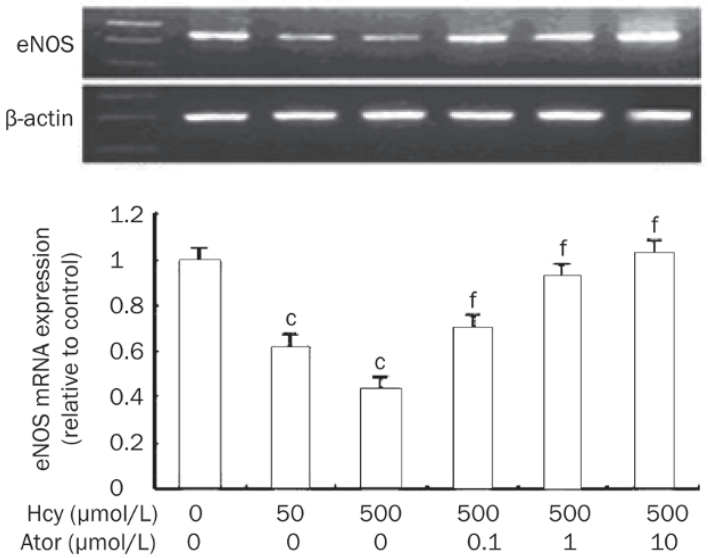

C
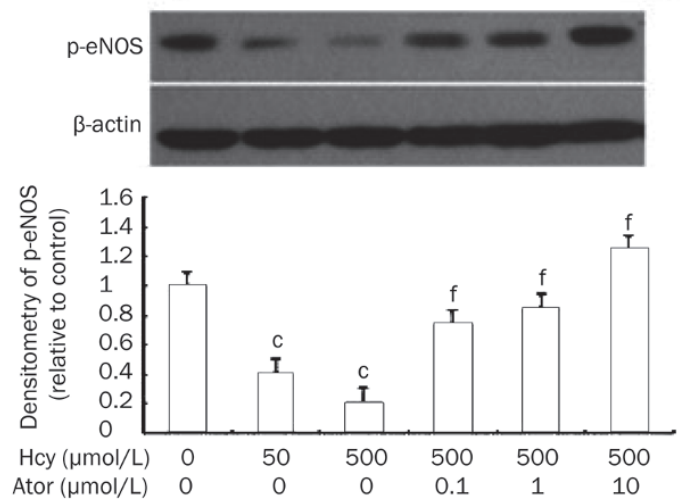

Figure 4. Atorvastatin increased NO production, eNOS mRNA and p-eNOS expression. (A) Effects of atorvastatin on Hcy-reduced NO within EPCs. Pretreatment of cells with atorvastatin $(0.1-10 \mu \mathrm{mol} / \mathrm{L}) 30 \mathrm{~min}$ prior to $500 \mu \mathrm{mol} / \mathrm{L}$ Hcy increased NO production. (B) Effects of atorvastatin on eNOS mRNA expression. Pretreatment of cells with atorvastatin (0.1-10 $\mu \mathrm{mol} / \mathrm{L}) 30 \mathrm{~min}$ prior to $500 \mu \mathrm{mol} / \mathrm{L}$ Hcy increased eNOS mRNA expression. The blots show the eNOS mRNA expression and the graphs show the quantification of the bands by densitometry. (C) Effects of atorvastatin on p-eNOS protein expression. Pretreatment of cells with atorvastatin (0.1-10 $\mu \mathrm{mol} / \mathrm{L}) 30 \mathrm{~min}$ prior to $500 \mu \mathrm{mol} / \mathrm{L} \mathrm{Hcy}$ increased p-eNOS expression. The blots show representative immunoblots of the phosphorylation of eNOS and the graphs show the quantification of the bands by densitometry. Date are normalized with $\beta$-actin so that value of the control group is regarded as 1.0. Results are the mean \pm SD from three independent experiments. ${ }^{c} P<0.01$ vs $0 \mu \mathrm{mol} / \mathrm{L}$ Hcy group. ${ }^{\mathrm{e}} P<0.05$, ${ }^{\mathrm{f}} P<0.01$ vs $500 \mu \mathrm{mol} / \mathrm{L}$ Hcy group. Ator: atorvastatin. atorvastatin groups: $6.2 \pm 0.2$-fold, $3.7 \pm 0.5$-fold, $2.6 \pm 0.4$-fold $v$ s $500 \mu \mathrm{mol} / \mathrm{L}$ Hcy group: $7.2 \pm 0.7$-fold; $P<0.05$ or $P<0.01$, Figure $5 B)$.

A
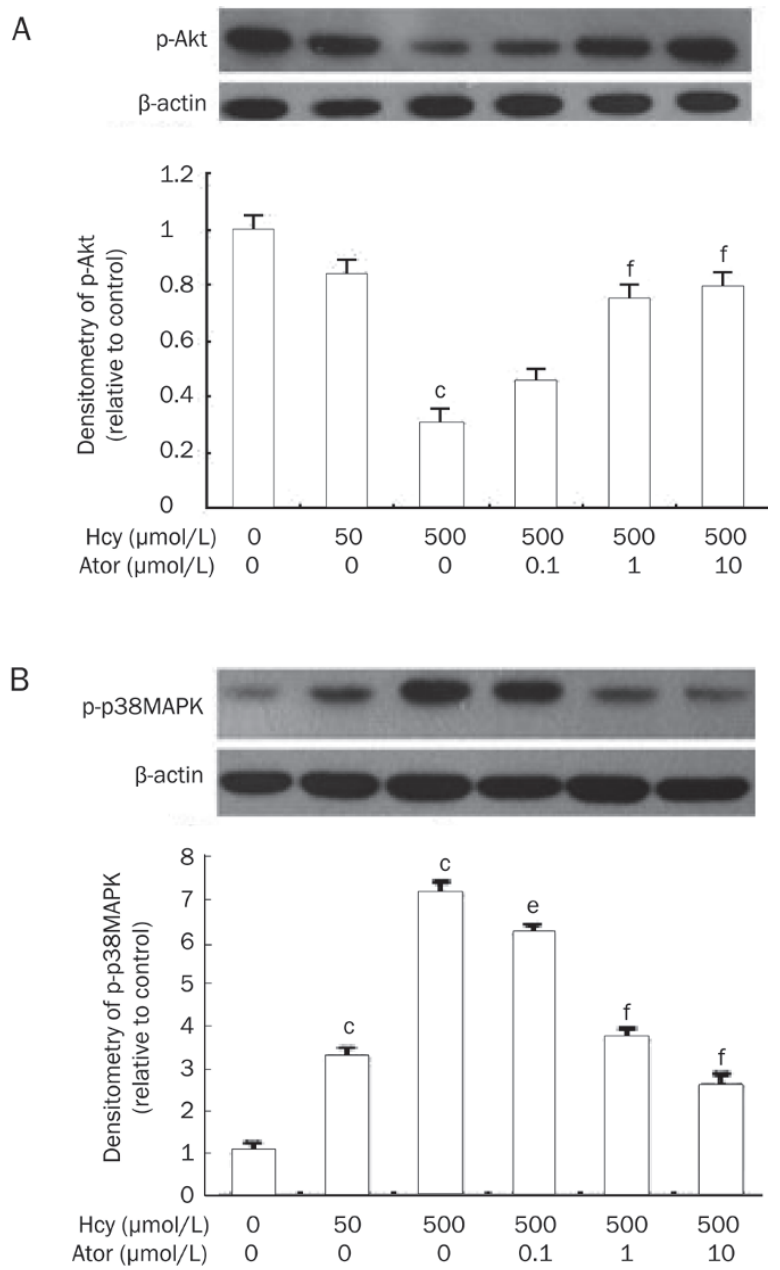

Figure 5. Atorvastatin increased p-Akt and decreased p-p38MAPK protein expression. (A) Effects of atorvastatin on $\mathrm{p}$-Akt protein expression. Pretreatment of cells with atorvastatin $(0.1-10 \mu \mathrm{mol} / \mathrm{L}) 30 \mathrm{~min}$ prior to $500 \mu \mathrm{mol} / \mathrm{L} \mathrm{Hcy} \mathrm{increased} \mathrm{p-Akt} \mathrm{protein} \mathrm{expression.} \mathrm{(B)} \mathrm{Effects} \mathrm{of}$ atorvastatin on p-p38MAPK protein expression. Pretreatment of cells with atorvastatin $(0.1-10 \mu \mathrm{mol} / \mathrm{L}) 30 \mathrm{~min}$ prior to $500 \mu \mathrm{mol} / \mathrm{L} \mathrm{Hcy}$ decreased $\mathrm{p}$-p38MAPK protein expression. The blots show representative immunoblots of the phosphorylation of p-Akt or p38MAPK and the graphs show the quantification of the bands by densitometry. Date are normalized with $\beta$-actin so that value of the control group is regarded as 1.0. Results are the mean \pm SD from three independent experiments. ${ }^{c} P<0.01$ vs 0 $\mu \mathrm{mol} / \mathrm{L} \mathrm{Hcy}$ group. ${ }^{\mathrm{e}} P<0.05,{ }^{f} P<0.01$ vs $500 \mu \mathrm{mol} / \mathrm{L}$ Hcy group. Ator: atorvastatin.

\section{Atorvastatin inhibited caspase- 3 activity}

The caspase family of cysteine proteases is a key player in the programmed cell death of numerous cell types, and caspase-3 has been proven to be the most important component of the caspase family. Therefore, we determined the activity of caspase-3 in Hcy-treated EPCs using a colorimetric activity assay 
kit. As shown in Figure 6, the activity of caspase-3 induced by $500 \mathrm{\mu mol} / \mathrm{L}$ Hcy was increased 4.12-fold. Moreover, this level of activation was suppressed by atorvastatin in a concentration-dependent manner $(0.1,1$, and $10 \mu \mathrm{mol} / \mathrm{L}$ atorvastatin groups: $3.1 \pm 0.8$-fold, $2.9 \pm 0.7$-fold, $2.6 \pm 0.5$-fold vs $500 \mu \mathrm{mol} / \mathrm{L}$ Hcy group: $4.2 \pm 0.7$-fold; $P<0.05$ or $P<0.01$ ).

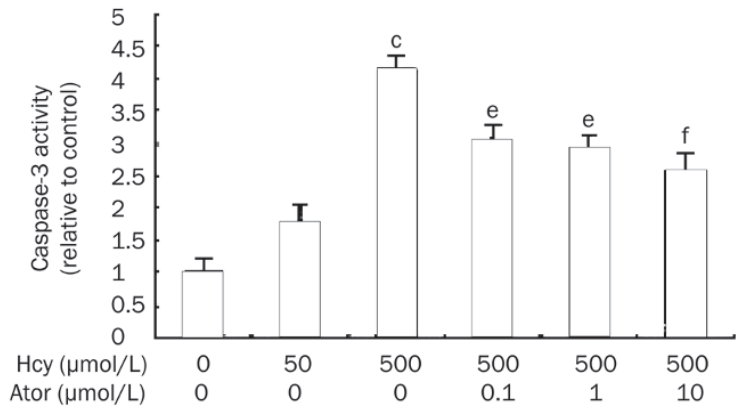

Figure 6. Atorvastatin inhibited caspase-3 activity. Pretreatment of cells with atorvastatin $(0.1-10 \mu \mathrm{mol} / \mathrm{L}) 30 \mathrm{~min}$ prior to $500 \mu \mathrm{mol} / \mathrm{L}$ Hcy inhibited activation of caspase-3. Results are the mean \pm SD from three independent experiments. ${ }^{\mathrm{c}} P<0.01$ vs $0 \mu \mathrm{mol} / \mathrm{L}$ Hcy group. ${ }^{\mathrm{e}} P<0.05,{ }^{\mathrm{f}} P<0.01$ vs $500 \mu \mathrm{mol} / \mathrm{L}$ Hcy group. Ator: atorvastatin.

\section{Discussion}

As an important source of renewing injured endothelial cells ${ }^{[2,3]}$, decreased peripheral EPC numbers and impaired EPC function have been shown to correlate with endothelial dysfunction and atherosclerosis ${ }^{[5]}$. Many risk factors for coronary artery disease have participated in this pathological process including HHcy ${ }^{[4-6]}$, but the effects of Hcy on EPCs have not been fully clarified until now. Recent studies have shown that Hcy accelerates the onset of EPC apoptosis and leads to cellular dysfunction ${ }^{[9,10]}$. In this study, we investigated the effects of Hcy on EPC proliferation, migration, in vitro vasculogenesis activity and apoptosis. We found that Hcy (50 and 500 $\mu \mathrm{mol} / \mathrm{L})$ significantly impaired cellular proliferation, migration, and in vitro vasculogenesis function, while Hcy (500 $\mu \mathrm{mol} / \mathrm{L})$ significantly induced EPC apoptosis. We also found that atorvastatin (0.1-10 $\mu \mathrm{mol} / \mathrm{L})$ improved EPC function and inhibited EPC apoptosis induced by Hcy in a concentrationdependent manner. Some reports have explained ${ }^{[13,14]}$ that the cytotoxicity of ROS plays a key role in EPC apoptosis, although EPCs are less sensitive to ROS induction compared with mature endothelial cells, such as HUVECs ${ }^{[12]}$. Our study also showed that ROS is strongly involved in Hcy-induced EPCs damage, since 50 and $500 \mu \mathrm{mol} / \mathrm{L}$ Hcy increased ROS production and NADPH oxidase activity in EPCs. Hcy may increase intracellular ROS by NADPH oxidase activation ${ }^{[15,26]}$, as shown by the membrane translocation of its p47 (phox) and p67 (phox) subunits ${ }^{[15,27]}$.

The balance between NO and oxidative stress plays a critical role in the maintenance of cardiovascular health. Our findings suggested that not only increased ROS but also impaired NO could contribute to the dysfunction and apoptosis of EPCs in the presence of Hcy. We found with in vitro cultivation that the decrease in NO concentrations could be associated with a very low proliferation, migration, and in vitro vasculogenesis capacity and with higher EPC apoptosis. A reduction in nitric oxide (NO) bioavailability has been linked to endothelial nitric oxide synthase (eNOS) uncoupling and NADPH oxidase activity $^{[17,28]}$. The NADPH oxidase system is the main source of ROS production in the vessel wall. With the activation of NADPH oxidase, cytosolic proteins translocate to the membrane and catalyze the transfer of one electron from NADPH to molecular oxygen, resulting in the formation of superoxide anion $\left(\mathrm{O}_{2}^{-}\right)$. As a result of eNOS uncoupling ${ }^{[17]}$, the transfer of one electron to molecular oxygen, instead of the five electron oxidation of $L$-arginine, promotes the generation of $\mathrm{O}_{2}^{-}$. At higher levels ${ }^{[28]}, \mathrm{O}_{2}{ }^{-}$will react with $\mathrm{NO}$ to form a cytotoxic peroxynitrite $\left(\mathrm{ONOO}^{-}\right)$, a main component of nitroxidative stress, which enhances oxidative stress and severely decreases NO. With a loss of NO bioavailability, there is enhanced susceptibility of the vessel to atherosclerotic processes, including smooth muscle cell proliferation and migration, expression of adhesion molecules, and platelet aggregation.

Atorvastatin, a synthetic HMG-CoA reductase inhibitor, is well tolerated, and adverse events are usually mild and transient. In dosages of 10 to $80 \mathrm{mg} /$ day (serum levels in humans range between 0.002 and $0.2 \mu \mathrm{mol} / \mathrm{L}$ ), atorvastatin can effectively reduce cholesterol levels and decrease morbidity and mortality in patients with CVD. Atorvastatin is shown to improve EPC function by lowering serum LDL as well as by mechanisms unrelated to lipid-lowering, including upregulating Akt/eNOS expression ${ }^{[10,18]}$ and reducing the formation of $\mathrm{O}_{2}{ }^{-[13]}$. Atorvastatin may inhibit Hcy-induced activation of NADPH oxidase and exert cellular antioxidant effects by decreasing the mRNA expression of the essential NADPH oxidase subunit Nox $1^{[29]}$ and inhibiting endothelial Nox4 overexpression and formatting an active complex with p22 (phox), which enhances superoxide anion formation and phosphorylation of $\mathrm{p} 38 \mathrm{MAPK}^{[30]}$.

In our study, Hcy decreased NO production in a supernatant of EPCs and decreased the expression of eNOS mRNA, p-eNOS, and p-Akt protein, suggesting that the eNOS translational and posttranslational mechanisms are both impaired by Hcy in EPCs. Our study also demonstrated that atorvastatin increased the expression of eNOS mRNA, p-eNOS, and p-Akt protein. Activation of Akt/eNOS plays a central role in NO bioavailability in EPCs, promoting the survival and mobilization of EPCs ${ }^{[10,18,19]}$. Previous research ${ }^{[18]}$ showed that statins upregulated eNOS by blocking Rho geranylgeranylation and by increasing Akt phosphorylation. Forkhead transcription factors (FOXO) are direct downstream targets of Akt and are inactivated by Akt-dependent phosphorylation of serine/ threonine residues. Akt inhibits FOXO transcription factors and subsequently stimulates the expression of eNOS ${ }^{[31,32]}$. Activation of Akt is available to phosphorylate eNOS at Ser 1177 , leading to eNOS activation and NO increase in $\mathrm{EPCs}^{[18]}$. Akt also suppresses the expression of mRNA for the p22phox 
subunit of NADPH oxidase ${ }^{[32]}$. Therefore, the notable decrease in the activity of NADPH oxidase and the inhibition of the production of ROS may be due to the activation of Akt. Furthermore, Akt dephosphorylation plays a major role in accelerating the senescence and reducing the proliferation of EPCs that is induced by $\mathrm{Hcy}^{[33]}$. Previous studies have shown that many downstream targets of Akt are involved in cell survival pathways, including (apoptosis signal-regulating kinase 1, ASK1), FOXO ${ }^{[18]}, \mathrm{NF}-\mathrm{kB}$, and the $\mathrm{p} 38 \mathrm{MAPK}^{[34]}$.

The stress-activated kinases p38MAPK are closely associated with apoptosis in many cell lines. Recent studies demonstrate that p38MAPK contributes to the reduction in the numbers and apoptosis of EPCs induced by TNF-a, OX-LDL and high glucose in in vitro culture assays ${ }^{[21,35]}$. Our data show that Hcy caused EPCs apoptosis and dysfunction accompanied by an increase in ROS and p-p38MAPK. All of these effects can be attenuated by atorvastatin. Therefore, we believe that the inhibitory effect of atorvastatin on the activation of p38MAPK might be related to its antioxidant function. It has been reported that ROS increase the phosphorylation of a tyrosine or/and serine of MAPK ${ }^{[20]}$, while siRNAs against NADPH oxidases ${ }^{[36]}$ suppress the phosphorylation of p38MAPK. Endogenous Nox $4^{[37]}$ has been located to the nucleus of endothelial cells, which pointed to the nucleus as an intracellular site of ROS production. The nuclear localization of Nox4 suggests that it might regulate gene expression and activate a serine/ threonine protein kinase through the production of ROS. Oxidative stress can directly or indirectly modulate p38MAPK activation, leading to phosphorylation of the downstream kinase mitogen- and stress-activated kinase (MSK) 1 and activation of a transcription factor cAMP-responsive elementbinding protein (CREB), which ultimately results in gene expression changes that influence cells to survive or die ${ }^{[20,21,35]}$.

Caspase- 3 belongs to a family of cysteine proteases and is involved in apoptosis. Therefore, to determine further downstream regulation, we detected caspase-3 activity by colorimetric assay. In EPCs treated with Hcy, we can easily detect different apoptosis characteristics, such as cytochrome-c release, caspase- 8 and/or caspase- 3 activation ${ }^{[9,10]}$. In agreement with previous studies $^{[9,10]}$, at the intracellular level we found that there was a 4.12-fold increase in caspase-3 activity with 500 $\mu \mathrm{mol} / \mathrm{L}$ Hcy on EPCs, which was significantly attenuated by atorvastatin. In this study, we showed that Hcy was cytotoxic and capable of inducing apoptotic cell death via the caspase-3 pathway. Our findings strongly suggest that atorvastatin exerts its anti-apoptosis activity through inhibiting caspace-3 activity.

In summary, our study suggests that the underlying protective effects of atorvastatin on EPCs involve reducing oxidative stress from Nox and up-regulating Akt/eNOS and down-regulating the p38MAPK/caspase-3 signaling pathway in EPCs in vitro. Furthermore, our results imply that oxidative stress is not the only factor that accounts for the initiation of apoptosis and the dysfunction of EPCs induced by Hcy. Impairment of NO-mediated vascular protection is also related to the effects of Hcy on EPCs. Additional mechanisms, such as an imbal- ance of anti-apoptotic/ proapoptotic factors and endoplasmic reticulum stress, need to be further elucidated.

\section{Author contribution}

Xiao-mei BAO designed the project, performed the research, analyzed the data, and wrote the paper. Chun-fang WU cultured the cells. Guo-ping LU partly designed the project and revised the paper.

\section{References}

1 Bao XM, Wu CF, Lu GP. Atorvastatin attenuates homocysteine-induced apoptosis in human umbilical vein endothelial cells via inhibiting NADPH oxidase-related oxidative stress-triggered p38MAPK signaling. Acta Pharmacol Sin 2009; 30: 1392-8.

2 Hill JM, Zalos G, Halcox JP, Schenke WH, Waclawiw MA, Quyyumi AA, et al. Circulating endothelial progenitor cells, vascular function, and cardiovascular risk. New Engl J Med 2003; 348: 593-600.

3 Walter DH, Rittig K, Bahlmann FH, Kirchmair R, Silver M, Murayama $\mathrm{T}$, et al. Statin therapy accelerates reendothelialization: a novel effect involving mobilization and incorporation of bone marrow-derived endothelial progenitor cells. Circulation 2002; 105: 3017-24.

4 Vasa M, Fichtlscherer S, Aicher A, Adler K, Urbich C, Martin H, et al. Number and migratory activity of circulating endothelial progenitor cells inversely correlate with risk factors for coronary artery disease. Circ Res 2001; 89: E1-7.

5 Werner N, Wassmann S, Ahlers P, Schiegl T, Kosiol S, Link A, et al. Endothelial progenitor cells correlate with endothelial function in patients with coronary artery disease. Basic Res Cardiol 2007; 102: 565-71.

6 Zhu J, Wang X, Chen J, Sun J, Zhang F. Reduced number and activity of circulating endothelial progenitor cells from patients with hyperhomocysteinemia. Arch Med Res 2006; 37: 484-9.

7 Tan H, Jiang X, Yang F, Li Z, Liao D, Trial J, et al. Hyperhomocysteinemia inhibits post-injury reendothelialization in mice. Cardiovasc Res 2006; 69: 253-62.

8 Chen JZ, Zhu JH, Wang XX. Effects of homocysteine on number and activity of endothelial progenitor cells from peripheral blood. J Mol Cell Cardiol 2004; 36: 233-9.

9 Alam MM, Mohammad AA, Shuaib U, Wang C, Ghani U, Schwindt B, et al. Homocysteine reduces endothelial progenitor cells in stroke patients through apoptosis. J Cereb Blood Flow Metab 2009; 29: 157-65.

10 Noor R, Shuaib U, Wang CX. High-density lipoprotein cholesterol regulates endothelial progenitor cells by increasing eNOS and preventing apoptosis. Atherosclerosis 2007; 192: 92-9.

11 Dernbach E, Urbich C, Brandes RP, Hofmann WK, Zeiher AM, Dimmeler $\mathrm{S}$, et al. Antioxidative stress-associated genes in circulating progenitor cells: evidence for enhanced resistance against oxidative stress. Blood 2004; 104: 3591-7.

12 He T, Peterson TE, Holmuhamedov EL, Terzic A, Caplice NM, Oberley LW, et al. Human endothelial progenitor cells tolerate oxidative stress due to intrinsically high expression of manganese superoxide dismutase. Arterioscler Thromb Vasc Biol 2004; 24: 2021-7.

13 Urbich C, Knau A, Fichtlscherer S, Walter DH, Brühl T, Potente M, et al. FOXO-dependent expression of the proapoptotic protein Bim: pivotal role for apoptosis signaling in endothelial progenitor cells. FASEB J 2005; 19: 974-6.

14 Yao EH, Yu Y, Fukuda N. Oxidative stress on progenitor and stem cells in cardiovascular diseases. Curr Pharm Biotechnol 2006; 7: 101-8.

15 Alvarez-Maqueda M, El Bekay R, Monteseirin J, Alba G, Chacón P, 
Vega A, et al. Homocysteine enhances superoxide anion release and $\mathrm{NADPH}$ oxidase assembly by human neutrophils. Effects on MAPK activation and neutrophil migration. Atherosclerosis 2004; 172: 22938.

16 Weiss N. Mechanisms of increased vascular oxidant stress in hyperhomocysteinemia and its impact on endothelial function. Curr Drug Metab 2005; 6: 27-36.

17 Cai H, Harrison DG. Endothelia dysfunction in cardiovascular disease: The role of oxidant stress. Circ Res 2000; 87: 840-4.

18 Ma FX, Chen F, Ren Q, Han ZC. Lovastatin restores the function of endothelial progenitor cells damaged by oxLDL. Acta Pharmacol Sin 2009; 30: 545-52.

19 de Nigris F, Balestrieri ML, Williams-Ignarro S, D'Armiento FP, Lerman LO, Byrns R, et al. Therapeutic effects of autologous bone marrow cells and metabolic intervention in the ischemic hindlimb of spontaneously hypertensive rats involve reduced cell senescence and CXCR4/Akt/eNOS pathways. J Cardiovasc Pharmacol 2007; 50: 424-33.

20 El-Remessy AB, Tang Y, Zhu G. Neuroprotective effects of cannabidiol in endotoxin-induced uveitis: critical role of p38 MAPK activation. Mol Vis 2008; 14: 2190-203.

21 Wu Y, Wang Q, Cheng L, Wang J, Lu G. Effect of oxidized low-density lipoprotein on survival and function of endothelial progenitor cell mediated by p38 signal pathway. J Cardiovasc Pharmacol 2009; 53: 151-6.

22 Davignon J. Beneficial cardiovascular pleiotropic effects of statins. Circulation 2004; 109: III39-43.

23 Dimmeler S, Aicher A, Vasa M, Mildner-Rihm C, Adler K, Tiemann M, et al. HMG-CoA reductase inhibitors (statins) increase endothelial progenitor cells via the PI 3-kinase/Akt pathway. J Clin Invest 2001; 108: 391-7.

24 Weis M, Heeschen C, Glassford AJ, Cooke JP. Statins have biphasic effects on angiogenesis. Circulation 2002; 105: 739-45.

25 Li L, Zhu DL, Shen WL, Gao PJ. Increased migration of vascular adventitial fibroblasts from spontaneously hypertensive rats. Hypertens Res 2006; 29: 95-103.

26 Ungvari Z, Csiszar A, Edwards JG, Kaminski PM, Wolin MS, Kaley $G$, et al. Increased superoxide production in coronary arteries in hyperhomocysteinemia: role of tumor necrosis factor-alpha, NADPH oxidase, and inducible nitric oxide synthase. Arterioscler Thromb Vasc Biol 2003; 23: 418-24.

27 Carluccio MA, Ancora MA, Massaro M, Carluccio M, Scoditti E, Distante A, et al. Homocysteine induces VCAM-1 gene expression through NF-kappaB and $\mathrm{NAD}(\mathrm{P}) \mathrm{H}$ oxidase activation: protective role of Mediterranean diet polyphenolic antioxidants. Am J Physiol Heart Circ Physiol 2007; 293: H2344-54.

28 Reiter CD, Teng RJ, Beckman JS. Superoxide reacts with nitric oxide to nitrate tyrosine at physiological $\mathrm{pH}$ via peroxynitrite. J Biol Chem 2000; 275: 32460-6.

29 Wassmann S, Laufs U, Müller K. Cellular antioxidant effects of atorvastatin in vitro and in vivo. Arterioscler Thromb Vasc Biol 2002; 22: $300-5$.

30 Goettsch C, Goettsch W, Muller G. Nox4 overexpression activates reactive oxygen species and p38 MAPK in human endothelial cells. Biochem Biophys Res Commun 2009; 380: 355-60.

31 Potente M, Urbich C, Sasaki K, Hofmann WK, Heeschen C, Aicher A, et al. Involvement of Foxo transcription factors in angiogenesis and postnatal neovascularization. J Clin Invest 2005; 115: 2382-92.

32 Shah DI, Singh M. Possible role of Akt to improve vascular endothelial dysfunction in diabetic and hyperhomocysteinemic rats. Mol Cell Biochem 2007; 295: 65-74.

33 Zhu JH, Chen JZ, Wang XX, Xie XD, Sun J, Zhang FR, et al. Homocysteine accelerates senescence and reduces proliferation of endothelial progenitor cells. J Mol Cell Cardiol 2006 40: 648-52.

34 Ingram DA, Krier TR, Mead LE, McGuire C, Prater DN, Bhavsar J, et al. Clonogenic endothelial progenitor cells are sensitive to oxidative stress. Stem Cells 2007; 25: 297-304.

35 Seeger FH, Haendeler J, Walter DH, Rochwalsky U, Reinhold J, Urbich C, et al. p38 mitogen-activated protein kinase downregulates endothelial progenitor cells. Circulation 2005; 111: 1184-91.

36 Bid MR, Spokes KC, Shih SC, Aird WC. NADPH oxidase activity selectively modulates vascular endothelial growth factor signaling pathways. J Biol Chem 2007; 282: 35373-85.

37 Kuroda J, Nakagawa K, Yamasaki T, Nakamura K, Takeya R, Kuribayashi F, et al. The superoxide-producing $\mathrm{NAD}(\mathrm{P}) \mathrm{H}$ oxidase Nox4 in the nucleus of human vascular endothelial cells. Genes Cells 2005; 10: 1139-51. 